\title{
Production of polyclonal anti- $\beta$-tubulin antibodies and immunodetection of Vairimorpha (Nosema) ceranae (Opisthosporidia: Microsporidia) prolife- rative stages in the midguts of Apis mellifera and in the Sf9 cell culture
}

\author{
Igor V. Senderskiy, Anastasiya N. Ignatieva, \\ Darya S. Kireeva and Viacheslav V. Dolgikh \\ All-Russian Institute of Plant Protection, 196608, St. Petersburg, Pushkin, Russia
}

| Submitted October 8, 2020| Accepted December 23, 2020|

\begin{abstract}
Summary
A number of methods to detect microsporidia infections are based on recovery of spores due to their thick refractive spore walls and presence of chitin that easily binds to fluorogenic and chromogenic stains. Visualization of intracellular stages in infected cells and organs has been always a challenge. In this report a new immunodetection method based on the use of $\beta$-tubulin antibodies, has been developed to mark the intracellular life cycle stages of Vairimorpha (Nosema) ceranae, an emergent pathogen of Apis mellifera. For this purpose, we carried out the heterologous expression of the V. ceranae $\beta$-tubulin gene in E. coli cells and obtained polyclonal antibodies to the recombinant protein. The antibodies were successfully applied for immunolabelling of microsporidian cells in insect midguts in vivo as well as in $\mathrm{Sf} 9$ cell culture in vitro.
\end{abstract}

Key words: honey bee nosemosis, immunofluorescence, Microsporidia, stages of intracellular development

\section{Introduction}

Microsporidia are a group of eukaryotic fungirelated intracellular parasites broadly distributed in the environment (Vavra and Larson, 2014). They infect almost all animal lineages and some unicellular hosts, such as amoebae and gregarines. Microsporidia infection is usually confirmed by microscopic examination of spores that have thick refractive envelope, so they can be easily detected by light microscopy observations. Due to the presence of chitin spores are usually stained with chromotrope-based trichrome (Garcia, 2002) and chemofluorescent agents like Calcofluor White M2R dye (Chen et al., 2017).

The proliferative stages of microsporidia are more difficult to detect in light microscope due to their small size and optical transparency. At the same time, visualization of intracellular stages is of great importance for the study of parasite-

doi:10.21685/1680-0826-2021-15-1-1 
host relationships. Traditional Giemsa staining of infected cells and tissue samples provides information only about the development of life cycle stages and can help to find a focus of infection in histological preparations. Transmission electron microscopy is considered to be the best approach for the visualization of parasites within host cells and investigation of their fine cytological structures, but hardly can be used at low intensity of infection.

Fluorescence in situ hybridization (FISH) is considered to be one of the most promising methods for detecting intracellular stages of microsporidia. FISH probes against microsporidia rRNA sequences allow locating parasites in tissue samples and even determining the phylogenetic position of the parasites as rRNA targeted regions may be speciesspecific (Gisder et al., 2011; Dubuffet et al., 2012). Another promising method of microsporidia visualization is immunofluorescence assay (IFA). This method is based on specific interactions between immunoglobulins and microsporidia proteins, followed by treatment with secondary antibodies conjugated with a fluorescent label. In a series of works, devoted to the metabolism and secretory proteins of Paranosema (Antonospora) locustae, antibodies against molecular chaperones Hsp70 were used to visualize infected cells and to separate parasites from host cytoplasm (Senderskiy et al., 2014a, 2014b). Recently, a novel method of labeling the proliferative stages of Nosema bombycis with $\beta$-tubulin antibodies was established (Chen et al., 2017). Beta-tubulin protein is widespread in the cytoskeleton as a major component of microtubules, which makes it a reliable marker of the parasite cell. The $\beta$-tubulin gene is conserved and yet variable enough to be used in molecular diagnostic protocols to detect microsporidia. For example, PCR detection methods of Nosema infection in silkworms (Esvaran et al., 2019) and Enterocytozoon hepatopenaei in shrimp (Han et al., 2019) basing on this gene, were developed. No cross reactivity of primers was observed when used with uninfected host DNA. Moreover this gene is applied in multigene phylogeny studies of crustacean parasites (Han et al., 2019) and multilocus genotyping of Nosema bombycis isolates (Tokarev et al., 2019).

In this study we proposed to exploit $\beta$-tubulin polyclonal antibodies for detection of intracellular stages of microsporidia Vairimorpha (Nosema) ceranae, an emergent pathogen of Apis mellifera. $V$. ceranae was first found in Asian honey bee Apis cerana (Fries et al., 1996). Then the parasite was discovered in western honey bee in Europe (Higes et al., 2006) and all over the world becoming one of the most common pathogens of A. mellifera (Klee et al., 2007; Martin-Hernandez et al., 2007). Novel microsporidia-suppressing strategies, based on RNA interference and recombinant antibodies, are directed to interfere with crucial metabolic enzymes of these parasites during their intracellular development (Paldi et al., 2010; Rodríguez-García et al., 2018; Huang et al., 2016, 2018). The development of such approaches requires establishing of tissue and cell culture parasite-host model systems (Becnel and Andreadis, 2014). The goal of this work was to demonstrate immunolabeling in $V$. ceranae infected tissues in vivo, and in cultured insect cells. As there are no available permanent hymenopteran cell lines, we used the heterologous lepidopteran-derived $\mathrm{Sf} 9$ cell culture proved to be susceptible to V. ceranae (Genersch et al., 2013).

To visualize $V$. ceranae intracellular stages by IFA we amplified and overexpressed full-size parasite $\beta$-tubulin in E. coli, produced polyclonal antibodies against the recombinant protein and used them to detect microsporidian cells in infected Sf9 lepidopteran cell culture as well as in A. mellifera midguts.

\section{Material and methods}

\section{Parasite isolation AND IDENTIFICATION}

Honey bees $A$. mellifera naturally infected with microsporidia $V$. ceranae were collected from hives of private apiaries in the Leningrad region. Spores were isolated as previously described (Tokarev et al., 2018), and investigated with bright field optics of the microscope Axio Imager M1 (Carl Zeiss, Germany) to distinguish them from Vairimorpha (Nosema) apis. To confirm the absence of $V$. apis spores in preparations, DNA was extracted and analyzed by PCR with DreamTaq Green PCR Master Mix (Thermo Fisher Scientific, MA). V. ceranae-specific primers $218 \mathrm{MITOC} \mathrm{F} / \mathrm{R}$ and $V$. apis-specific primers 312APIS F/R (Martín-Hernández et al., 2007) were applied. DNA extraction and PCR program parameters were the same as in the previous study (Tokarev et al., 2018). For further work, only $V$. ceranae positive $V$. apis free samples were used.

Heterologous expression of $V$. ceranaE $\beta$-Tubulin IN BACTERIA

The gene encoding $V$. ceranae $\beta$-tubulin (Gen Bank accession number KKO76433.1), was ampli- 
fied by PCR using isolated genomic DNA, Phusion Flash High-Fidelity PCR Master Mix (Thermo Fisher Scientific, MA), the forward primer CAAG GATCCATGAGAGAAATAATTCACCT ACAA and the reverse primer TCACTCGAGT TAATTAA CGAATAAGTCTTCTGAATCT (BamHI and XhoI restriction sites are underlined). Amplification was performed using Tercyc PCR thermal cycler (DNATechnology, Russia) with following parameters: initiation denaturation at $92{ }^{\circ} \mathrm{C}$ for $3 \mathrm{~min}$, followed by 30 cycles of denaturation at $92{ }^{\circ} \mathrm{C}$ for $30 \mathrm{sec}$, annealing at $54{ }^{\circ} \mathrm{C}$ for $45 \mathrm{sec}$, elongation at $72{ }^{\circ} \mathrm{C}$ for $30 \mathrm{sec}$ and a final extension at $72{ }^{\circ} \mathrm{C}$ for $10 \mathrm{~min}$. The PCR product of about $1300 \mathrm{bp}$ was purified from $2 \%$ agarose gel, inserted into the pRSETa expression vector (Thermo Fisher Scientific, MA) at BamHI/ XhoI sites and sequenced using T7 forward and reverse primers.

The constructed plasmid was transformed into E. coli BL21 (DE3)-derived C41 cells (Miroux and Walker, 1996) via electroporation at $1700 \mathrm{~V}$ using Electroporator 2510 (Eppendorf, Germany). Positive colonies selected on LB plates containing $0.15 \mathrm{mg} / \mathrm{ml}$ ampicillin were inoculated in $100 \mathrm{ml}$ of the same liquid broth. The culture was grown in an orbital shaker at $220 \mathrm{rpm}$ and $37^{\circ} \mathrm{C}$ to $\mathrm{OD}_{600}$ of 0.4 , and expression was induced by addition of $0.7 \mathrm{mM}$ isopropyl $\beta$-D-1-thiogalactopyranoside (IPTG, final concentration) followed by cultivation for 15 h at $37^{\circ} \mathrm{C}$.

After expression, bacterial cells were pelleted by centrifugation at $3,000 \mathrm{~g}$ for $15 \mathrm{~min}$, sonicated in $50 \mathrm{mM}$ Tris- $\mathrm{HCl}$ (pH 7.4) buffer solution (TB) and centrifuged at $14,000 \mathrm{~g}$ for $15 \mathrm{~min}$ at $4{ }^{\circ} \mathrm{C}$. The insoluble inclusion bodies were carefully washed in TB and the recombinant protein was dissolved by resuspending the pellet in $8 \mathrm{M}$ urea followed by removal of insoluble debris at $14,000 \mathrm{~g}$ for $5 \mathrm{~min}$. Samples for SDS-PAGE from the supernatant and the pellet of bacterial homogenate were prepared. Pellet has been resuspended in TB and urea in the supernatant volume. Sample preparation, SDSPAGE and immunoblotting with monoclonal antibodies against polyhistidine sequence (SigmaAldrich, MO) diluted 1:2000 was carried out as it was described previously (Senderskiy et al., 2014b).

Production AND PURIFICATION OF POLYClONAL ANTIBODIES

Recombinant protein was dissolved in $8 \mathrm{M}$ urea to a concentration of $16 \mathrm{mg} / \mathrm{ml}$, diluted twentyfold with TB, mixed with an equal volume of Freund's adjuvant (complete for first injection, incomplete for the following ones) and used for immunization. Rabbit was immunized by four intramuscular injections ( $0.4 \mathrm{mg}$ protein per injection) at 10 -day intervals. Ten days after the last immunization, $15 \mathrm{ml}$ of blood were collected and the serum was analyzed by immunoblotting. Specific antibodies were purified against recombinant protein and transferred to a nitrocellulose membrane as described previously (Dolgikh et al., 2009, 2011). The concentration of recombinant protein, extracted from inclusion bodies, was determined by Bradford's assay (Bradford, 1976).

\section{HONEY BEE INFECTION}

For experiments on artificial infection A. mellifera carnica brood was obtained from a private housekeeper in Belarus. The absence of natural microsporidia infection was confirmed by selective examination using microscopy and PCR. Foraging bees were planted in 0.51 plastic bottles and then fed sugar solution supplemented with $V$. ceranae spores. A standard infection doze was one million spores per bee.

Ten days post-infection bees were dissected to isolate midguts for IFA and immunoblotting. For immunoblotting, midguts were homogenated in TB and heated at $95^{\circ} \mathrm{C}$ for $10 \mathrm{~min}$ with an equal volume of $2 \times$ sample buffer (125 mM Tris- $\mathrm{Cl}$ (pH 6.8), 4\% SDS, 10\% 2-mercaptoethanol, 20\% glycerol). For IFA the midguts were fixed in PBS (phosphatebuffered saline) with $4 \%$ paraformaldehyde (Serva, Germany) for $24 \mathrm{~h}$, washed in PBS, incubated in $30 \%$ sucrose for cryoprotection, and frozen in liquid nitrogen. Frozen sections (10 $\mu \mathrm{m}$ thickness) were prepared with the Microm HM 520 cryotome and placed on microscope slides. Immunoblotting and IFA with newly raised antibodies were performed as described before (Senderskiy et al., 2014b; Timofeev et al., 2017) in three independent infection experiments.

\section{Cell culture infection}

Sf9 cell line derived from fall armyworm Spodoptera frugiperda (Lepidoptera: Noctuidae) pupal ovarian tissue, was obtained from ECACC General collection (ECACC 89070101). Cells were cultured in Sf900III SFM (Thermo Fisher Scientific, MA) and maintained according to manufacturer's inst- 
ructions. Cells for infections were in the mid-log phase growth and their viability was over $90 \%$.

$V$. ceranae spores for cell culture infections were obtained from artificially infected living bees. After midgut dissection and homogenization in distilled water, spores were additionally purified on $50 \%$ Percoll gradient and sterilized with antiseptic Multicide for 30 min followed by washing in sterile water. Then $10^{8}$ spores in water were dried in a well of 6-well plate for $30 \mathrm{~min}$ and cell suspension has been added at a ratio of 1 cell per 200 spores. In 5-day post-infection the cells were separated from spores using $20 \%$ Percoll gradient.

The cells were fixed for $24 \mathrm{~h}$ by the addition of $8 \%$ paraformaldehyde (Serva, Germany) prepared in PBS to an equal volume of cell suspension. IFA with polyclonal antibodies was carried out as previously described (Timofeev et al., 2017). The experiments on in vitro infection followed by fixation and IFA were independently repeated 3 times.

\section{Results and discussion}

The full-size gene encoding $V$. ceranae $\beta$-tubulin, was amplified by PCR using specific primers and genomic DNA as a template. Sequencing of the cloned DNA fragment confirmed its correct amplification and insertion into pRSETa vector at $\mathrm{BamHI}$ /XhoI sites in the frame with an $\mathrm{N}$-terminal $4 \mathrm{kDa}$ peptide containing a polyHis tag.

After the transformation of E. coli $\mathrm{C} 41$ cells by this construct and subsequent heterologous expression, recombinant $\beta$-tubulin was accumulated in the inclusion bodies but not in the soluble fraction of bacteria broken by sonication (Fig.1, lanes 1,2). This finding simplified the procedure of protein isolation. Inclusion bodies were just pelleted from the disrupted cells by centrifugation, carefully washed and recombinant protein was easily dissolved in $8 \mathrm{M}$ urea (Fig. 1, lane 3). Isolation of inclusion bodies from $100 \mathrm{~mL}$ of bacterial culture yielded approximately $16 \mathrm{mg}$ of the recombinant product.

The solubilized $\beta$-tubulin was used to generate rabbit immune antiserum. Immunoblotting of purified polyclonal antibodies against nitrocellulose bands with immobilized recombinant protein, demonstrated that isolated antibodies specifically recognized a protein with a mass approximately 50 $\mathrm{kDa}$ in the samples of $A$. mellifera midgut infected with microsporidia (Fig. 1, lane 4). The size of this band corresponded to $V$. ceranae $\beta$-tubulin molecular weight $(49.2 \mathrm{kDa})$ predicted according to its

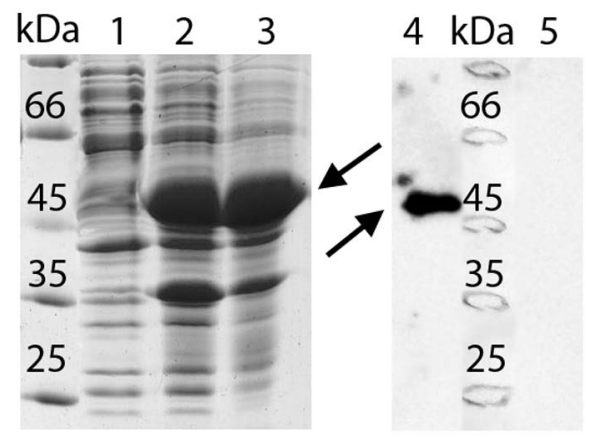

Fig. 1. SDS-PAGE of recombinant Vairimorpha (Nosema) ceranae $\beta$-tubulin protein (lanes 1-3) and immunoblotting with Apis mellifera midgut extract (lanes 4, 5). Lane 1 - soluble fraction of sonicated E. coli cells, 2 - insoluble fraction of sonicated E. coli cells, 3 - inclusion bodies dissolved in $8 \mathrm{M}$ urea, 4 - infected midgut extract, 5 - uninfected (control). $\beta$-tubulin protein is indicated by arrows.

amino acid sequence. This protein band was not detected in midguts of uninfected (control) bees (Fig. 1, lane 5).

Immunofluorescence assay was performed on cryosections of infected midguts of $A$. mellifera. Antibodies to parasite $\beta$-tubulin specifically labeled stages of intracellular development (meronts and sporonts). The pattern of $\beta$-tubulin antibodies staining was not homogeneous (Fig. 2, A). Consistent clusters of filaments were observed in the cytoplasm around the nuclear area. The maximum density of fluorescent signal was concentrated at the periphery of the cell, closer to the plasma membrane, displaying the irregular ring structure. Likely, this rings corresponded to the elongated shape of merogonal stages. Spores and sporoblasts remained unstained as their envelope were impermeable for immunoglobulins.

Incubation of Sf9 cells with previously dried $V$. ceranae spores resulted in low rate of infection (about one percent). However, IFA provided an easy way to find even a single infected cell on entire preparation. Microsporidian proliferative stages developed in lepidopteran (Sf9) cell culture, demonstrated the same pattern of anti- $\beta$-tubulin staining, as naturally infected gastric epithelial cells of A. mellifera (Fig. 2, B).

The sequencing of some microsporidian genomes and genes enabled production of antibodies against parasite proteins expressed in heterologous systems. Due to a small size of microsporidia cells 

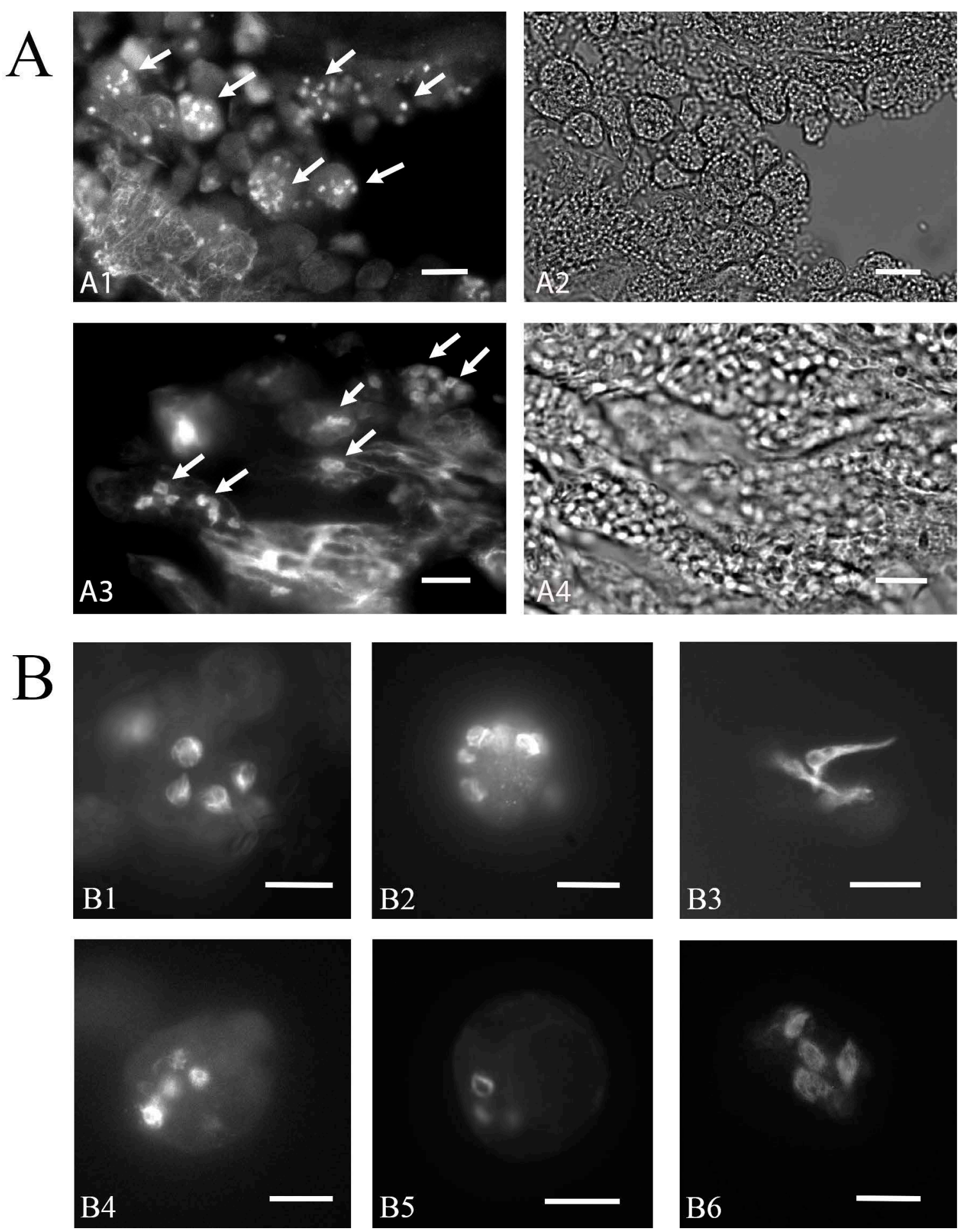

Fig. 2. Immunodetection of Vairimorpha (Nosema) ceranae intracellular stages. Cryosections of infected Apis mellifera midguts and Sf9 cells were stained with polyclonal $\beta$-tubulin antibodies, followed by treatment with secondary antibodies conjugated with Alexa Fluor 488 fluorescent label. A - Intracellular stages of $V$. ceranae (indicated by arrows) are seen in gastric epithelial cells; A1, A3 - fluorescence; A2, A4 - bright field microscopy. B - Infected Sf9 cells with intracellular stages of $V$. ceranae; immunolabeling with $\beta$-tubulin antibodies reveals clusters of filaments that mimic the shape of parasite's cell. Scale bars: A1-A4 $-20 \mu \mathrm{m}, \mathrm{B} 1-\mathrm{B} 6-10 \mu \mathrm{m}$. 
and spores, the most convenient method to precisely localize parasite proteins is immunoelectron microscopy (IEM). At the same time, IFA does not require such expensive equipment as IEM and is much more suitable for diagnostics. Besides, immunofluorescent microscopy is indispensable for co-localization of studied microsporidian proteins with other parasite or host cells molecules and/ or organelles and compartments. In our previous study (Senderskiy et al., 2014b) we used antibodies against Hsp70 molecular chaperone to visualize microsporidia Paranosema (Antonospora) locustae proliferative stages in host cell cytoplasm. To detect Nosema bombycis proliferative stages in infected silkworms and cell cultures, chinese authors used antibodies against microsporidian $\beta$-tubulins (Chen et al., 2017; Huang et al., 2018). In this study, we applied the same approach to detect $V$. ceranae intracellular stages in infected host tissues and cell culture. This method should help in testing new approaches to suppress $V$. ceranae intracellular development, in finding parasite secretome proteins, as well in immunodiagnostics of microsporidian early infection in honey bees and other hosts.

\section{Acknowledgments}

The research was supported by Russian Science Foundation, grant \# 18-16-00054.

\section{References}

Becnel J.J. and Andreadis T.G. 2014. Microsporidia in Insects. In: Microsporidia: Pathogens of Opportunity (Eds: Weiss L.M. and Becnel J.J.). USA: Wiley-Blackwell. 521-570.

Bradford M. 1976. A rapid and sensitive method for the quantitation of protein utilizing the principle of protein-dye binding. Anal. Biochem. 72, 248-254.

Chen J., Guo W., Dang X., Huang Y., Liu F., Meng X., An Y., Long M., Bao J., Zhou Z., Xiang Z. and Pan G. 2017. Easy labeling of proliferative phase and sporogonic phase of microsporidia Nosema bombycis in host cells. PloS ONE. 2017. 12, 6. e0179618.

Dolgikh V.V., Seliverstova E.V., Naumov A.M., Senderskiy I.V., Pavlova O.A. and Beznous-senko G.V. 2009. Heterologous expression of pyruvate dehydrogenase E1 subunits of the microsporidium Paranosema (Antonospora) locustae and im- munolocalization of the mitochondrial protein in amitochondrial cells. FEMS Microbiol. Lett. 293, 285-291.

Dolgikh V.V., Senderskiy I.V., Pavlova O.A., Naumov A.M. and Beznoussenko G.V. 2011. Immunolocalization of an alternative respiratory chain in Antonospora (Paranosema) locustae spores: mitosomes retain their role in microsporidial energy metabolism. Eukaryot. Cell. 10, 588-593.

Dubuffet A., Smith J.E., Solter L., Perotti M.A., Braig H.R. and Dunn A.M.2013. Specific detection and localization of microsporidian parasites in invertebrate hosts by using in situ hybridization. Applied and environmental microbiology. 79, 385388. Epub 2012/10/23. https://doi.org/10.1128/ AEM.02699-12 PMID: 23087031.

Esvaran V.G., Mohanasundaram A., Mahadeva S., Gupta T., Kangayam M. and Ponnuvel K.M. 2019. Development and comparison of real-time and conventional PCR tools targeting b-tubulin gene for detection of Nosema infection in silkworms. J. Parasit. Dis. 43, 31-38.

Fries I., Feng F., daSilva A., Slemenda S.B., and Pieniazek N.J. 1996. Nosema ceranae n. sp. (Microspora, Nosematidae), morphological and molecular characterization of a microsporidian parasite of the Asian honey bee Apis cerana (Hymenoptera, Apidae). Eur. J. Protistol. 32, 356-365.

Garcia L.S. 2002. Laboratory identification of microsporidia. J. Clin. Microbiol. 40, 1892-1901.

Genersch E., Gisder S., Hedtke K., Hunter W.B., Möckel N., and Müller U. 2013. Standard methods for cell cultures in Apis mellifera research. J. Apic. Res. 52, 1-8.

Gisder S., and Genersch E.2015. Identification of candidate agents active against $N$. ceranae infection in honey bees: establishment of a medium throughput screening assay based on $N$. ceranae infected cultured cells. PLoS ONE. 10, 2. e0117200.

Gisder S., Möckel N., Linde A,. and Genersch E. 2011. A cell culture model for Nosema ceranae and Nosema apis allows new insights into the life cycle of these important honey bee-pathogenic microsporidia.Environ. Microbiol. 13, 404-413.

Han J.E., Tang K.F.J. and Kim J.H. 2018. The use of beta-tubulin gene for phylogenetic analysis of the microsporidian parasite Enterocytozoon hepatopenaei (EHP) and in the development of a nested PCR as its diagnostic tool. Aquaqulture. 495, 899-902.

Higes M., Martin-Hernandez R., and Meana A. 2006. Nosema ceranae, a new microsporidian parasite in honey bees in Europe. J. Invertebr. 
Pathol. 92, 93-95.

Higes M., Garcia-Palencia P., Martin-Hernandez R. and Meana A. 2007. Experimental infection of Apis mellifera honey bees with Nosema ceranae (Microsporidia). J. Invertebr. Pathol. 94, 211-217.

Huang Q., Chen Y., Neumann P. and Evans J.D. 2016. Effective silencing of dicer decreases spore load of the honey bee parasite Nosema ceranae. Fungal Genomics Biol. 6, 1-4.

Huang Y., Chen J., Sun B., Zheng R., Li B., Li Z., Tan Y., Wei J., Pan G., Li C. and Zhou Z. 2018. Engineered resistance to Nosema bombycis by in vitro expression of a single-chain antibody in Sf9-III cells. PLoS ONE. 13, 2. e0193065.

Klee J., Besana A.M., Genersch E., Gisder S., Nanetti A., Tam D.Q., Chinh T.X., Puerta F., Ruz J.M., Kryger P., Message D., Hatjina F., Korpela S., Fries I. and Paxton R.J. 2007. Widespread dispersal of the microsporidian Nosema ceranae, an emergent pathogen of the western honey bee, Apis mellifera. J. Invertebr. Pathol. 96, 1-10. http:// dx.doi.org/10.1016/j.jip.2007.02.014.

Martin-Hernandez R., Meana A., Prieto L., Martinez Salvador A., Garrido- Bailon E. and Higes M. 2007. Outcome of colonization of Apis mellifera by Nosema ceranae. Appl. Environ. Microbiol. 73, 6331-6338. doi: org/10.1128/AEM.00270-07.

Miroux B. and Walker J.E. 1996. Over-production of proteins in Escherichia coli: mutant hosts that allow synthesis of some membrane proteins and globular proteins at high levels. J. Mol. Biol. 260, 289-298. https://doi.org/10.1006/jmbi.1996.0399.

Paldi N., Glick E., Oliva M., Zilberberg Y., Aubin L., Pettis J., Chen Y. and Evans J.D. 2010. Effective gene silencing in a microsporidian parasite associated with honeybee (Apis mellifera) colony declines. Appl. Environ. Microbiol. 76, 5960-5964. https://doi.org/10.1128/AEM.01067-10.

Rodríguez-García C., Evans J.D., Li W., Branchiccela B., Li J.H., Heerman M.C., Banmeke
O., Zhao Y., Hamilton M., Higes M., MartínHernández R. and Chen Y.P. 2018. Nosemosis control in European honey bees, Apis mellifera, by silencing the gene encoding Nosema ceranae polar tube protein 3. J. Exp. Biol. 221. jeb184606. https:// doi.org/10.1242/jeb.184606.

Senderskiy I.V., Pavlova O.A., Timofeev S.A. and Dolgikh V.V. 2014. Immunolocalization of microsporidium Paranosema locustae Canning Hsp70 family proteins in locust infected fat body. Parazitologiya. 48, 63-70 (in Russian with English summary).

Senderskiy I.V., Timofeev S.A., Seliverstova E.V., Pavlova O.A. and Dolgikh V.V. 2014. Secretion of Antonospora (Paranosema) locustae proteins into infected cells suggests an active role of microsporidia in the control of host programs and metabolic processes. PLoS ONE. 9, 4. e93585.

Timofeev S.A., Senderskiy I.V., Tsarev A.A., Tokarev Y.S. and Dolgikh V.V. 2017. Heterologous expression of Paranosema (Antonospora) locustae hexokinase in lepidopteran sf9 cells is followed by accumulation of the microsporidian protein in insect cell nuclei. J. Invertebr. Pathol.143, 104-107.

Tokarev Y.S., Mirzahodjaev B.A., Senderskiy I.V., Malysh S.M., Ismatullaeva D.A., Dadazhanova D.Kh. and Dolgikh V.V. 2019. Multilocus genotyping of Nosema bombycis infecting silkworm Bombyx mori in Uzbekistan. Abstr. IV All-Russian Plant Protection Congress. P. 231.

Tokarev Y.S., Zinatullina Z.Y., Ignatieva A.N., Zhigileva O.N., Malysh Y.M. and Sokolova Y.Y. 2018. Detection of two microsporidia pathogens of the European honey bee Apis mellifera (Insecta: Apidae) in Western Siberia. Acta Parasitol. 63, 728732. doi:10.1515/ap-2018-0086.

Vavra J. and Larsson J.I.R. 2014. Structure of Microsporidia. In: Microsporidia: Pathogens of Opportunity (Eds: Weiss L.M. and Becnel J.J.). USA: Wiley-Blackwell. 1-70.

Address for correspondence: Igor V. Senderskiy. All-Russian Institute of Plant Protection, Podbelskogo 3, 196608, St. Petersburg, Pushkin, Russia; e-mail: senderskiy@mail.ru. 